\title{
Measurement of Sub-23 nm Particulate Emissions from GDI Engines: A Comparison of Processing Methods
}

\author{
Author, co-author (Do NOT enter this information. It will be pulled from participant tab in \\ MyTechZone)
}

Affiliation (Do NOT enter this information. It will be pulled from participant tab in MyTechZone)

\begin{abstract}
Engine research has increasingly focused on emission of sub $23 \mathrm{~nm}$ particulates in recent years. Likewise, current legislative efforts are being made for particulate number (PN) emission limits to include this previously omitted size range. In Europe, PN measurement equipment and procedures for regulatory purposes are defined by the particle measurement programme (PMP). Latest regulation drafts for sub 23 $\mathrm{nm}$ measurements specify counting efficiencies with a $65 \%$ cut-off size at $10 \mathrm{~nm}(\mathrm{~d} 65)$ and a minimum of $90 \%$ above $15 \mathrm{~nm}$ (d90). Even though alternative instruments, such as differential mobility spectrometers (DMS), are widely used in laboratory environments, the interpretation of their sub $23 \mathrm{~nm}$ measurements has not yet been widely discussed. For this study, particulate emissions of a $1.0 \mathrm{~L}$ gasoline direct injection (GDI) engine have been measured with a DMS system for low to medium speeds with two load steps. While the particle size distribution (PSD) at the higher load conditions exhibited a bimodal shape, the PSD for the other conditions was unimodal with a peak position below $30 \mathrm{~nm}$. Lognormal fitting of nucleation and accumulation modes previously yielded results comparable to the established PMP, with d50 and d90 of $23 \mathrm{~nm}$ and $41 \mathrm{~nm}$, respectively. However, this approach was found not suitable for sub $23 \mathrm{~nm}$ PN measurements due to incorrect assignment of the nucleation and accumulation modes. Recent literature suggests digital filtering of the PSD from DMS. Here, a modified filtering equation is proposed based on the latest legislative proposals. Subsequently, the new filter was compared with filters for both PMP equivalent and sub $23 \mathrm{~nm}$ processing of DMS data. Compared to the latter, results with the new filter showed up to $17 \%$ higher PN emissions and up to $13.6 \mathrm{~nm}$ lower geometric mean diameter (GMD) of the PSD.
\end{abstract}

\section{Introduction}

Particulate emissions pose a significant challenge in the development of internal combustion engines. Carbonaceous particles or soot can form within the combustion chamber due to incomplete combustion [1]. While the parameters influencing this phenomenon are multifold, the formation of soot can often be attributed to insufficient mixing of the air-fuel mixture and fuel impingement on the cylinder walls or piston head [2]. Most particulates in the exhaust gas are fuel derived, however, some particles stem from the combustion of oil and wear of the metal surfaces [3].

It is generally accepted that the first precursor to soot formation is the molecule acetylene, which forms from the decomposition of hydrocarbon fuel [4]. Acetylene is involved in a complex series of radical and polymerization reactions, eventually forming Polycyclic Aromatic Hydrocarbons (PAHs) [4,5]. As these species continue to increase in size, they nucleate to form the first soot particulates that emerge from the vapor phase - this is the inception of the nucleation mode [6]. Surface growth from the addition of vapor-phase species occurs alongside continued nucleation and coalescence of the initial particulates [7], increasing the size but decreasing the overall number of particles [8]. This leads to the formation of the spherical primary particle, which is the basic structural unit of soot. Primary particles are typically 20-50 $\mathrm{nm}$ in diameter [9], and possess a structure comprising an inner core and an outer shell [10]. The core generally contains several carbon spherules, remnants of the initial nucleation mode particles, surrounded by distorted layers of disordered carbon [11]. The outer shell is formed from graphitic microcrystallites, 2-5 carbon layers thick, arranged concentrically around the core [10,12]. In some studies of gasoline direct injection (GDI) engine soot an additional layer of amorphous carbon, up to $5 \mathrm{~nm}$ thick, has been observed outside of the typical 'outer shell' layer [13]. Surface growth continues alongside aggregation from the collision of primary particles [14], and leads to the formation of the typical fractal-like soot nanoparticles this is the accumulation mode. Oxidation in the high-temperature environment of the cylinder pervades the formation process [15], acting to reduce overall soot size and mass, and reduce elemental diversity via carbonization [4].

Once emitted from the engine, particulate emissions have profound implications for the ecosystem in various ways. Suspended in higher levels of the atmosphere, solid particulates contribute to climate change as they strongly absorb solar radiation [16]. If absorbed by water, soot can strongly affect microbial processes by acting as active sites for adsorption of organic molecules [17]. With regards to human health, soot particles are carcinogenic and the smallest particles can even transfer into the bloodstream and circulate to other organs [18]. Moreover, combustion generated particles can also directly impact engine performance. Soot can transfer into the lubricating oil via the oil film on the cylinder walls and via blow-by gases through the gap between piston and cylinder [19]. The transferred particles are involved in complex interactions with performance-enhancing additives in the lubricating oil, which has been seen to lead to significant changes in friction coefficient [20] and viscosity [21]. Soot entrainment can also greatly increase the wear rate, especially for components with thin oil films such as the timing chain, thus affecting functionality [19].

In the European Union, legislative efforts initially focused on particulate mass (PM) emissions of diesel engines with the Euro 1 regulation [22], due to their historically higher emissions levels compared to gasoline port fuel injection engines [23]. The PM measurement approach was implemented by collecting particulates on a filter membrane in a specified test setup and weighing of the filter before and after the test to determine the total quantity of deposits. This relatively simple methodology enabled monitoring of the initial regulations. However, the technique was considered to provide insufficient reliability for the subsequent reduction in PM limits [24]. Instead, particulate number (PN) emission limits were introduced with 
Euro 3 [25]. The new measurement approach enabled further limits on the emission of particulates to be set but also presented new technical challenges due to the high sensitivity to the sampling procedure. The uncertainty was found to stem to a considerable extent from volatile species in the exhaust gas [26]. These species could occur as a distinct particle (nucleation) mode or as a condensate onto existing particles [27], both shifting the particle size distribution (PSD) and affecting the total particle number. To ensure repeatable measurements, the particle measurement programme (PMP) was developed to define a standardized setup [26]. The PMP prescribes the use of a volatile particle remover (VPR) and cut-off sizes for particle detectors, commonly condensation particle counters (CPC). Both elements were included to improve the robustness of the method by eliminating artefacts stemming from volatile species. The cut-off limits are defined as detecting $50 \%$ of particles at $23 \mathrm{~nm}$ and more than $90 \%$ of particles at $41 \mathrm{~nm}$. These counting efficiencies are referred to as d50 and d90, respectively.

The emission regulations include limits for the total number of particles emitted - the latest Euro $6 \mathrm{~d}$ states $6 \times 10^{11} \# / \mathrm{km}$ as the permissible level [28]. While this provides a clear threshold value for vehicle approval, further information on the distribution of particle sizes (i.e. the PSD) can be required for research purposes. Knowledge of the PSD can help to design particulate filters with optimized filtration efficiencies [29]. Moreover, formation processes and soot characteristics can be related to specific engine operating conditions [30]. Hence, alternative instruments are often used in research settings as compared to standardized equipment for legislative compliance tests. In addition to particle detectors, these instruments also incorporate components to differentiate particle sizes, such as differential mobility analyzers (DMA) and differential mobility spectrometers (DMS) [31]. The former device filters the sample gas for a specific size at a time and collects the sample PSD by scanning through the available size range. DMAs are used in combination with particle detectors such as CPCs. In contrast, DMSs facilitate a series of electrometers to resolve the entire PSD of a sample gas simultaneously. The additional information of the PSD obtained by either type of instrument comes at the expense of additional postprocessing steps to extract the total PN levels comparable to the legislative approach. This primarily involves the recorded particle numbers for size classes below $41 \mathrm{~nm}$ due to the more sensitive detection limits of DMA and DMS, often reaching as low as $5 \mathrm{~nm}$ [31]. The following remarks primarily focus on the processing of data collected from a DMS, specifically a DMS500 by Cambustion, due to the prevalence of this instrument in the research environment and previous works on its data processing. However, the underlying method is assumed to be applicable for processing of PSDs obtained by any instrument.

The Cambustion DMS500 classifier column contains 22 electrodes that enable a detectable size range of $5 \mathrm{~nm}$ to $1000 \mathrm{~nm}$. However, the recorded electrometer currents must first be converted to particle sizes. The manufacturer software provides two analysis options for this step: Linear approximation and lognormal parameterization. The former approach facilitates a series of 38 discrete size classes ranging from $4.85 \mathrm{~nm}$ to $1000 \mathrm{~nm}$, while the latter uses one or multiple continuous lognormal functions. Both approaches utilize an instrument transfer function or inversion matrix that is unique to each instrument. It is determined based on empirical calibration data as well as underlying models of charging and classification. The relevant calculations for the processing itself are detailed by Symonds et al. [32]. Employing lognormal functions enables describing distributions with sets of two simple metrics: count median diameter (CMD) and geometric standard deviation (GSD), i.e. peak position and width. For internal combustion engines, two peaks are commonly considered: nucleation mode and accumulation mode. The software for resolving the PSD into separate modes considers a probability map of CMD and GSD to classify the individual peaks.
Despite the lack of a VPR, DMS500 measurements were found to be similar to PMP compliant measurements if only the accumulation mode is considered [23]. This step is considered as a "software" VPR as the nucleation mode with its volatile fraction is removed [33]. However, an accurate representation of the data with a lognormal fit is not necessarily guaranteed. Limiting factors can be the shape of the underlying PSD as well as the boundary conditions of the probability map.

An alternative approach to achieving results that are comparable to PMP measurements is digital filtering of the linear approximation spectrum. This method was first proposed by Leach [34]. It entails a counting efficiency function that is applied to the spectrum and implements the counting efficiencies as for a PMP compliant CPC (i.e. $\mathrm{d}_{50}=23 \mathrm{~nm}$ and $\mathrm{d}_{90}=41 \mathrm{~nm}$ ). This processing method has been found to deliver more representative results than using the accumulation mode only [34] and was also successfully used in subsequent studies by Leach et al. [35-37]. The function is based on the structure of a Wiebe function; a zero-dimensional or energy balance model for the mass fraction burned of an engine. The proposed modified function was proposed as shown in Equation 1, where $d_{p}$ is particle diameter.

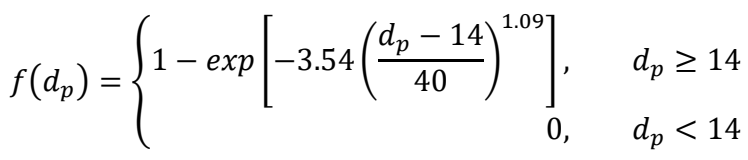

As outlined above, a current research focus lies on the presence and characterization of sub $23 \mathrm{~nm}$ particulates. Due to the absence of a VPR in the established DMS500 setup, the validity of nucleation mode particle measurements is limited due to the possibility of volatile artefacts. However, given the availability of data collected with this equipment, Leach et al. [38] proposed two modified counting efficiency functions. The first function is based on $\mathrm{d}_{50}=10 \mathrm{~nm}$ and $\mathrm{d}_{90}$ $=23 \mathrm{~nm}$ which were used in JRC and PMP research activities leading up to 2018 [39]. The second function facilitates $\mathrm{d}_{50}=10 \mathrm{~nm}$ and $\mathrm{d}_{90}=$ $15 \mathrm{~nm}$ which were proposed in a PEMs4Nano report in 2017 [40]. The first and second function are included below as Equation 2 and 3, respectively.

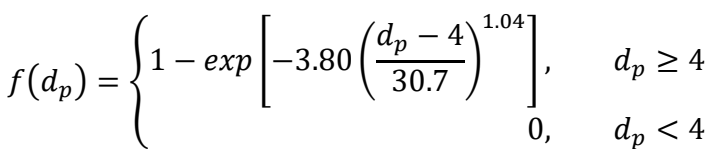

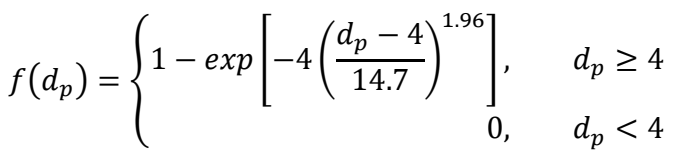

The two new functions were applied to data sets that had been processed previously with the PMP inspired function. The counted PN increased by ca. $10 \%$ to $20 \%$ for lower loads with naturally aspirated engine operation, while PN increases of ca. $30 \%$ to $70 \%$ were found for boosted operation with part load and higher loads [38]. It was noted that the second function (i.e. Equation 3 ) generally counted $9 \%$ higher $\mathrm{PN}$ compared to the first function (i.e. Equation 2). Since this study was published, CPC counting efficiencies were proposed for an updated PMP protocol to include sub $23 \mathrm{~nm}$ solid particles: $\mathrm{d}_{65}=10$ $\mathrm{nm}$ and $\mathrm{d}_{90}>15 \mathrm{~nm}$. Hence, an updated filtering equation would be required to reflect the proposed counting efficiencies.

The objective of this paper is to determine such a function that is suitable for the proposed counting efficiencies. Moreover, a detailed comparison of the digital filtering approach with the lognormal fitting method is to be carried out. A particular focus in this study will be placed on the effect on the fraction of sub $23 \mathrm{~nm}$ particulates as well as the GMD position. 


\section{Experimental}

\section{Engine Setup}

The experiments were carried out on a $1.0 \mathrm{~L}$ three-cylinder GDI engine with variable valve timing (VVT). The specifications of the engine are presented in Table 1. The engine was installed on an engine testbed and the power take-off shaft was directly connected to a Froude Consine EC38 TA Eddy-Current dynamometer with a rated capacity of $154 \mathrm{~kW}$. The dynamometer was regulated by a Froude Texcel V4 controller in engine speed mode. The engine itself was controlled by a Bosch MED17 engine control unit (ECU) with mapping as per manufacturer calibration. Pedal input to the ECU was controlled using a digital pedal input from a computer.

Table 1. Specifications of the three-cylinder GDI engine.

\begin{tabular}{ll}
\hline Parameter & Value \\
\hline Max. Power & $92 \mathrm{~kW} @ 6000 \mathrm{rpm}$ \\
Max. Torque & $170 \mathrm{Nm} @ 1400-4500 \mathrm{rpm}$ \\
Bore & $71.9 \mathrm{~mm}$ \\
Stroke & $82.0 \mathrm{~mm}$ \\
Total Capacity & $999 \mathrm{~cm}^{3}$ \\
Compression Ratio & $10.5: 1$ \\
Injector & 5 -hole solenoid \\
Max. Injection Pressure & $200 \mathrm{bar}($ common rail) \\
EVC, VVT Range & $0-60{ }^{\circ} \mathrm{CA}$ aTDC \\
IVO, VVT Range & $-40-20{ }^{\circ} \mathrm{CA}$ aTDC \\
Intake / Exhaust Duration & $240{ }^{\circ} \mathrm{CA} / 248{ }^{\circ} \mathrm{CA}$ \\
\hline
\end{tabular}

To measure in-cylinder pressure, piezoelectric Kistler 6045 pressure transducers were installed in all three cylinders. The signals of the transducers were amplified by Kistler Type 5018 charge amplifiers. The engine was further equipped with a Hohner Automation optical shaft encoder with a resolution of $0.5{ }^{\circ} \mathrm{CA}$ for crank angle (CA) resolved data acquisition. To monitor the injection current signal, a Fluke i30s current clamp was used. The fuel flow to the engine was measured with a Micro Motion CMFS010M mass flow sensor in combination with a Micro Motion 2700 transmitter. Temperatures of engine coolant, lubricating oil, intake air, and exhaust gas were measured with K-type thermocouples.

Four test conditions (TCs) were used for this study. These include two load levels of idling and $40 \mathrm{Nm}$, respectively. Each load was tested at two speeds of $1500 \mathrm{rpm}$ and $2000 \mathrm{rpm}$. Before assessing the test conditions, the engine was conditioned by running with $20 \mathrm{Nm}$ at 1750 rpm until engine oil reached $85^{\circ} \mathrm{C}$.

\section{Particulate Measurement}

Particulate emissions were measured with a Cambustion DMS500. The sampling block for initial gas conditioning was mounted to the exhaust pipe after the turbocharger to directly measure engine-out emissions. The instrument itself was connected to the sampling block via a $5 \mathrm{~m}$ sampling line. Both the sampling line and block were heated to $191{ }^{\circ} \mathrm{C}$ to avoid condensation of water and volatile species. The sampling block contained a first dilution stage and a cyclone, removing particles larger than $1000 \mathrm{~nm}$. The initial dilution stage was fixed at 5:1 and supplied with HEPA filtered compressed air. The secondary dilution stage of the DMS500 was bypassed, i.e. set to 1:1, to achieve acceptable signal strength. Measurements were acquired over a window of $60 \mathrm{~s}$ with a sampling frequency of $0.5 \mathrm{~Hz}$. To account for particle losses in the heated sampling line, a penetration efficiency model was applied (see Figure 1). This model was provided by Cambustion and is based on the work of Kumar et al. [41].

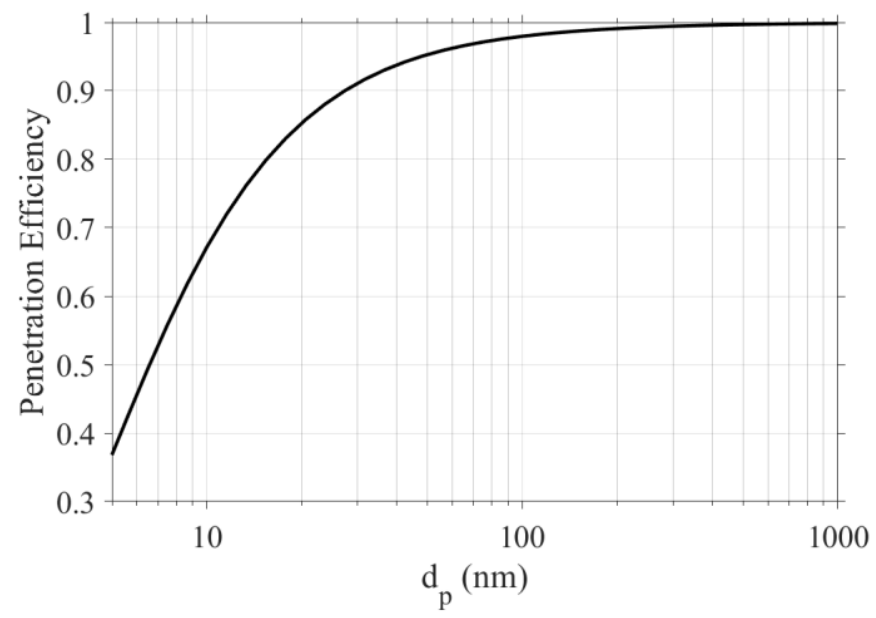

Figure 1. Correction model for penetration efficiencies of particles to the DMS, provided by Cambustion.

\section{Results and Discussion}

\section{Engine Test Metrics}

Engine operating parameters and additional measurements from all test conditions are reported in Table 2. For the higher load case, the injection pressure almost doubled to the maximum pressure of $200 \mathrm{bar}$, the spark timing was delayed by ca. $15^{\circ} \mathrm{CA}$, and the valve overlap was increased by up to $64{ }^{\circ} \mathrm{CA}$. The temperature of coolant liquid and lubricating oil were regulated by the ECU. While the coolant temperature remained similar for the test cases, the temperature of the oil increased slightly for increased engine speed and load. As to be expected, fuel consumption increased similarly with speed and load. The coefficient of variance $(\mathrm{CoV})$ is considerably higher for the idling conditions due to higher influence of the cycle-to-cycle variation of pumping and friction losses compared to the net indicated mean effective pressure (IMEPn).

Table 2. Summary of measured engine metrics for the test conditions (TCs).

\begin{tabular}{lccccc}
\hline Parameter & Unit & TC1 & TC2 & TC3 & TC4 \\
\hline Speed & rpm & 1750 & 1750 & 2250 & 2250 \\
Load & Nm & 1.0 & 39.6 & 0.7 & 40.2 \\
Spark & ${ }^{\circ} \mathrm{CA}$ bTDC & 39.2 & 23.2 & 39.8 & 24.5 \\
EVC & ${ }^{\circ} \mathrm{CA}$ aTDC & 30.0 & 50.0 & 30.0 & 50.0 \\
IVO & ${ }^{\circ} \mathrm{CA}$ aTDC & 20.3 & -19.0 & 20.4 & -24.1 \\
SOI & ${ }^{\circ} \mathrm{CA}$ bTDC & 259 & 264 & 274 & 269 \\
Inj. Pressure & $\mathrm{bar}$ & 115 & 200 & 117 & 200 \\
Inj. Duration & $\mu \mathrm{s}$ & 297 & 977 & 280 & 972 \\
IMEPn & $\mathrm{bar}$ & 0.88 & 5.87 & 0.88 & 6.01 \\
CoV & $\%$ & 42.9 & 2.8 & 23.8 & 1.1 \\
CA50 & ${ }^{\circ} \mathrm{CA} \mathrm{aTDC}$ & 14.3 & 5.9 & 15.3 & 6.3 \\
T-Coolant & ${ }^{\circ} \mathrm{C}$ & 89.0 & 89.2 & 89.7 & 89.4 \\
T-Oil & ${ }^{\circ} \mathrm{C}$ & 84.9 & 87.1 & 85.5 & 88.6 \\
T-Intake & ${ }^{\circ} \mathrm{C}$ & 33.8 & 31.7 & 32.4 & 31.3 \\
T-Exhaust & ${ }^{\circ} \mathrm{C}$ & 353 & 449 & 384 & 493 \\
Fuel Consumption & $\mathrm{kg} / \mathrm{h}$ & 0.65 & 1.95 & 0.84 & 2.48 \\
\hline
\end{tabular}




\section{Discrete Size Spectra}

Henceforth, the discrete size spectrum as obtained by linear approximation is referred to as the (raw) PSD. The PSDs for all operating conditions are shown as time series plots in the first column of Figure 2. For the higher load-level of TC2 and TC4, two separate peaks can be observed in the respective PSD. The first mode ranges predominantly from $5 \mathrm{~nm}$ to $20 \mathrm{~nm}$ with a peak at $8.5 \mathrm{~nm}$ and $5.5 \mathrm{Nm}$ for TC2 and TC4, respectively. The second mode includes mostly particles between $80 \mathrm{~nm}$ and $200 \mathrm{~nm}$ for TC2 and $70 \mathrm{~nm}$ to $600 \mathrm{~nm}$ for TC4, with the peak for both at ca. $180 \mathrm{~nm}$. The particle concentration of the first mode is similar for both TCs with $3.59 \times 10^{5} \# / \mathrm{cm}^{3}$ and $3.90 \times 10^{5} \# / \mathrm{cm}^{3}$ for TC2 and TC4, respectively. However, the second mode is considerably more pronounced for TC4 with $1.23 \times 10^{5} \mathrm{\#} / \mathrm{cm}^{3}$ compared to $2.59 \times 10^{4} \# / \mathrm{cm}^{3}$. The lower mode appears to be relatively stable over the $60 \mathrm{~s}$ measurement window with respect to size position and particle concentration for both TCs. The higher mode exhibits more variability in its width of particle sizes as well as concentrations.

In contrast, the PSDs for the idling load-level of TC1 and TC3 exhibit a unimodal shape. The particle concentration of the PSD peak is noticeably higher than for the higher load TCs by one order of magnitude, with peaks of $2.51 \times 10^{6} \# / \mathrm{cm}^{3}$ and $1.53 \times 10^{6} \# / \mathrm{cm}^{3}$ for TC1 and TC3, respectively. Moreover, the position of these peaks is at marginally higher particle size with $10 \mathrm{~nm}$ and $11.5 \mathrm{~nm}$ for the two respective TCs. For TC 3 a distinct drop in concentration around $50 \mathrm{~nm}$ can be observed that is consistent for the measurement window. A more gradual shift towards larger particle sizes can be observed in the time-series plot for TC1. However, the size distribution also exhibits some degree of variability in terms of particle concentration.

\section{Lognormal Fittings}

Two lognormal functions, for nucleation and accumulation mode (i.e. NM and AM), were fitted for all four TCs. The obtained fits are plotted along with the discrete linear approximation PSDs and presented in the second column of Figure 2. In addition, the geometric mean diameters (GMD) for both the lognormal fits and the linear approximation are presented in Table 3. For the idling load conditions TC1 and TC3, the fitting of two separate modes is not beneficial due to their unimodal PSDs. This is further supported by the close alignment of the GMD of their NM fit with the linear approximation GMD; these differ by only $1.1 \mathrm{~nm}$ for TC1 and $0.6 \mathrm{~nm}$ for TC3. However, no appreciable accumulation mode can be observed in the PSD and thus the AM fit is not meaningful. For higher load TC2 and TC4, the NM fits do not match the PSD as good as for the idle conditions: The peak concentration is below the PSD mode concentration and the position is marginally shifted. Due to the second mode in the size spectra, the GMD for the linear approximation becomes less meaningful. The AM fits become useful in this case. For TC2, the AM fit closely matches the linear approximation for particle sizes above $80 \mathrm{~nm}$. The peak position of the AM fit for TC4 is similarly well aligned, however, the fit distribution is wider than the mode in the raw PSD.

Table 3. Geometric mean diameters (GMD) for the nucleation mode (NM) and the accumulation mode (AM) lognormal fits as well as the discrete linear approximation for the four test conditions (TCs).

\begin{tabular}{lcccc}
\hline & \multicolumn{4}{c}{ GMD $(\mathrm{nm})$} \\
Processing Method & TC1 & TC2 & TC3 & TC4 \\
\hline Lognormal Fit (NM) & 10.5 & 9.7 & 12.4 & 7.9 \\
Discrete Lin. Approx. & 11.6 & 12.8 & 13.0 & 26.2 \\
Lognormal Fit (AM) & 49.4 & 168.5 & 46.7 & 195.3 \\
\hline
\end{tabular}

\section{Digital Filtering Function}

An alternative approach to processing the lognormal fitting can be found in applying size filtration functions digitally in the data postprocessing. Instead of attempting to resolve the PSD with a series of distinct modes, the digital filtration functions impose specified counting efficiencies. This processing step mimics the prescribed counting efficiencies of CPCs as outlined by the PMP. Rather than discarding volatile species using a nucleation mode, the filtration functions gradually reduce the extent to which particulate counts are included for smaller size classes. Leach et al. [35-37] successfully applied the method, after having initially proposed it in 2014, to obtain results comparable to the PMP method, i.e. for particles larger than 23 $\mathrm{nm}$ (counting efficiencies $\mathrm{d}_{50}=23 \mathrm{~nm}$ and $\mathrm{d}_{90}=41 \mathrm{~nm}$ ). Their digital filtration model, as stated above in Equation 1, will be referred to in the following as "Filter A". A focus in the current development of future emissions regulations is to include solid particulates below 23 $\mathrm{nm}$, prompting a series of research projects in this area. As part of one of these, the PEMs4Nano program, a report was published in 2017 proposing lower counting efficiencies of $\mathrm{d}_{50}=10 \mathrm{~nm}$ and $\mathrm{d}_{90}=15 \mathrm{~nm}$ in combination with additional changes [40]. Leach et al. [38] subsequently developed modified digital filtration models in 2019, with one filter equation based on these in 2017 proposed counting efficiencies. This filter is stated above in Equation 3 and will be referred to as "Filter B" in the following. Throughout early- to mid2020 , proposals for a new measurement protocol was discussed in meetings of the UN/ECE [42,43] and relevant reports [44]. This protocol includes lowered counting efficiencies of $\mathrm{d}_{65}=10 \mathrm{~nm}$ and $\mathrm{d}_{90}$ $>15 \mathrm{~nm}$. To reflect these likely updated regulations, a modified digital filtration model is here proposed with the following equation:

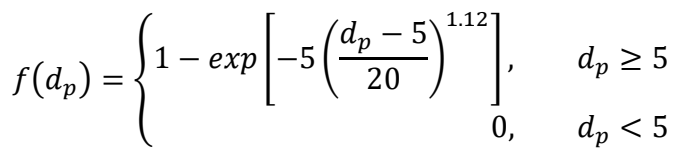

This equation was designed based on the shape of Filter A, having previously yielded data comparable to the PMP, as well as counting efficiency curves presented in the UN/ECE meeting [43]. The newly proposed filter is visualized in Figure 3 as "Filter C" alongside the two aforementioned filters. The inverse exponential shape of Filter $\mathrm{C}$ facilitates the increased counting efficiency of $65 \%$ at $10 \mathrm{~nm}$ compared to $50 \%$ of Filter B with an S-shape. Integration of the filter efficiency curve areas reveals that the change from Filter B to Filter $\mathrm{C}$ results in a counting efficiency increase of $6.7 \%$ for particles below $23 \mathrm{~nm}$. From Figure 3 it can further be noted that even Filter A includes particles below $23 \mathrm{~nm}$ to a small extent. However, the cumulative counting of particles in this size range with Filter A represents only $18 \%$ of the cumulative counting efficiency with Filter C.

Subsequently, the three filters were applied to the discrete linear approximations, i.e. the raw PSDs, of the four TCs, displayed in Figure 4. The filtered PSDs closely match the raw PSDs above the $\mathrm{d} 90$ of the respective filter, $41 \mathrm{~nm}$ for Filter A and $15 \mathrm{~nm}$ for both Filter B and Filter C. Below this point, the filtering effect becomes apparent.

Filter A removes the concentration of particles below $20 \mathrm{~nm}$ most noticeably, as intended for modelling the regulations of the PMP. For TC1 and TC 3 the single mode is shifted in its position from under 10 $\mathrm{nm}$ to just over $20 \mathrm{~nm}$. Moreover, the particle concentration of the mode peak is reduced by more than an order of magnitude. The concentration of the mode at $8 \mathrm{~nm}$ for TC2 is reduced to the same level as the larger particle size mode at above $100 \mathrm{~nm}$. Moreover, its position is shifted to just above $20 \mathrm{~nm}$ as for TC1 and TC3. Due to the lower particle mode position at below $6 \mathrm{~nm}$ for the PSD of TC4, the change to this mode is more considerable. The mode is removed as such and the particle concentrations below $50 \mathrm{~nm}$ only form a trailing end of the second mode just below $200 \mathrm{~nm}$. 

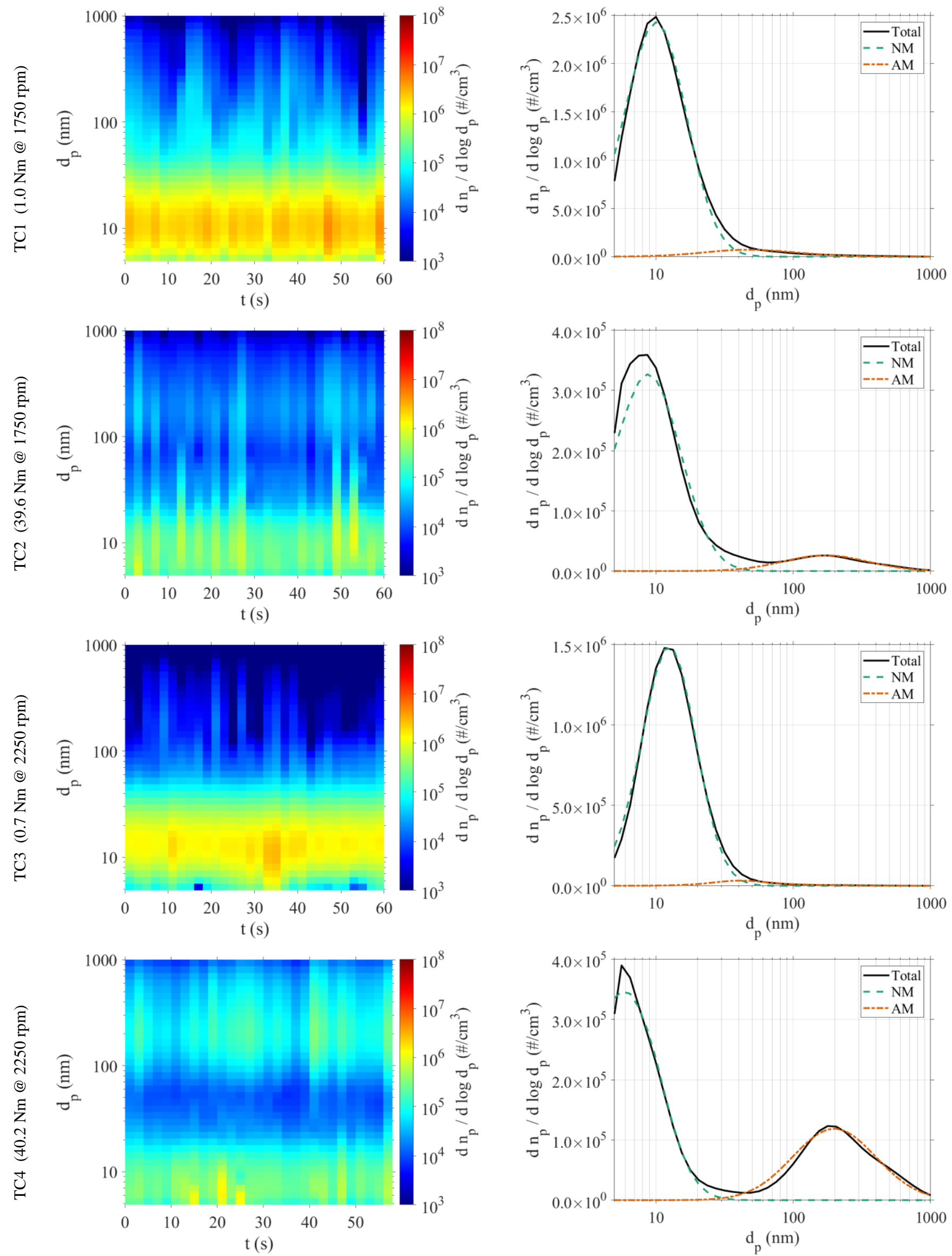

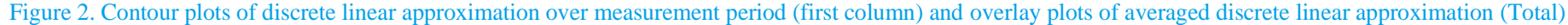
with lognormal fitted nucleation mode (NM) and accumulation mode (NM) for each of the four test conditions (TCs). 
The lowered counting efficiency setpoints of Filter B and Filter C change the filtration effect on the PSD shape. The single mode in TC1 and TC 3 is shifted to $12 \mathrm{~nm}$ for Filter B and $10.5 \mathrm{~nm}$ for Filter C. The flattened mode in TC2 remains as a peak with Filter B and Filter C. Similarly, the mode for TC4 is only reduced in concentration and shifted rather than being cut off at around $12 \mathrm{~nm}$. The difference between the PSDs as obtained from Filter B and Filter C becomes larger the lower the mode position. The change with the newly proposed filter is small for TC3, with a mode position at $12 \mathrm{~nm}$. However, an increase in mode peak concentration of almost $50 \%$ can be observed for TC4, with a mode position below $6 \mathrm{~nm}$.

Further insight into the differences between the filtration models and processing methods can be obtained by comparing the respective total PN (Table 4), the PN fraction of sub $23 \mathrm{~nm}$ particulates (Table 5), and the GMD (Table 6).

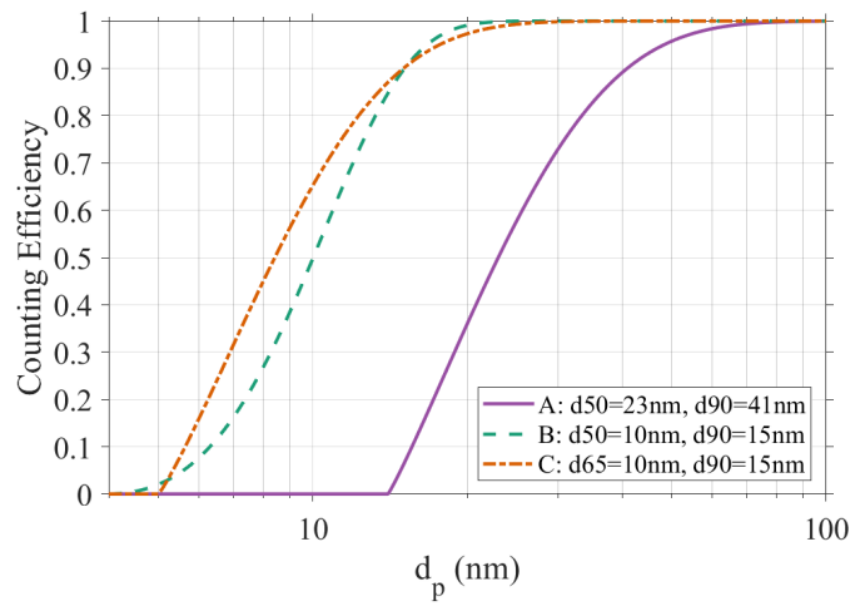

Figure 3. Comparison of the counting efficiencies of the digital filter functions.

As to be expected, the total PN continuously increases when moving from AM lognormal fit to Filter A, B, and C. The most noticeable differences can be observed for the idling load conditions TC1 and TC3 which only contain a smaller particle size mode. For these the processing with Filter A yields an almost $2.5 \mathrm{x}$ increase in total $\mathrm{PN}$ for TC1 and more than fivefold increase for TC3 than with the AM lognormal fit. The change from Filter A to B again increases the total $\mathrm{PN}$, by a factor of just below 5. Applying the newly proposed Filter C leads to an increase of more than $10 \%$ as compared to Filter B. Despite the significant increases in total PN, even with Filter C, the filtered PN is only $64 \%$ and $73 \%$ of the linear approximation PN for TC1 and TC3, respectively. These observed increases in total PN can be largely attributed to including a higher fraction of sub $23 \mathrm{~nm}$ particles. The lognormal AM contains $15 \%$ and $11 \%$ of such particulates for $\mathrm{TC} 1$ and TC3, respectively. With Filter A the sub $23 \mathrm{~nm}$ fraction is $32 \%$ and $40 \%$ for TC1 and TC3, respectively. The fraction increases with Filter $\mathrm{B}$ to $81 \%$ and $82 \%$ for the two respective filters. Filter C further increases the fraction of sub $23 \mathrm{~nm}$ particulates for these two TCs by up to $3 \%$. For comparison, the fraction of such particulates in the raw PSDs is $89 \%$ and $88 \%$ for TC1 and TC3, respectively. With higher fractions of smaller particles in the PSD, the GMD also decreases. The GMD for the lognormal AM fit is just below $50 \mathrm{~nm}$ for both TC and almost halves with the subsequent steps to Filter A and Filter B. Applying Filter $\mathrm{C}$ further reduces the GMD by a smaller among, from $15.7 \mathrm{~nm}$ to $14.5 \mathrm{~nm}$ for TC1 and $15.8 \mathrm{~nm}$ to $15.0 \mathrm{~nm}$ for TC3.

The changes with different processing methods manifest differently for TC2 and TC4 due to the overall lower level of particulate concentrations and the presence of an accumulation type particle mode in the PSDs. For TC2, the total PN increase by $67 \%$ with Filter A as compared to the lognormal AM fit and triple with the subsequent application of Filter B. Filter C elevates the total PN by a further $17 \%$
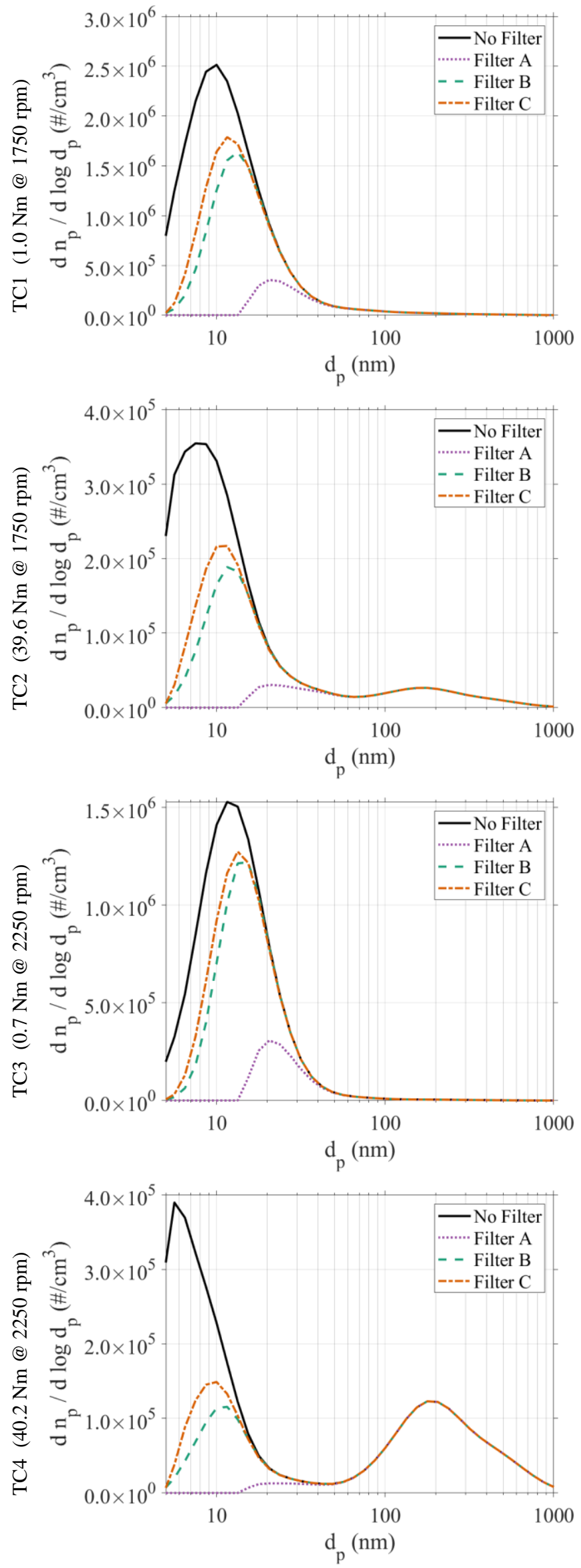

Figure 4. Overlay plots of the averaged discrete linear approximations with applied filters for each of the four test conditions (TCs). Filter A: $d_{50}=23 \mathrm{~nm}$, $d_{90}=41 \mathrm{~nm}$. Filter $B: d_{50}=10 \mathrm{~nm}, d_{90}=15 n$ m. Filter $C: d_{65}=10 \mathrm{~nm}, d_{90}=15 n$. 
but still reduced the total PN to $58 \%$ of the value of the discrete linear approximation. These differences are smaller than for TC1 and TC3 yet comparable to an extent. The reason for this similarity is the relatively small magnitude of the accumulation type mode in the PSD of TC2. Consequently, different observations are to be expected for TC4 with a more pronounced accumulation type mode. The total PN as obtained with the lognormal AM fit and with Filter A are within $0.3 \%$. Applying Filter B only increases the total PN 50\% as compared to multifold increases for the other TCs. However, Filter $\mathrm{C}$ still yields an increase of $9 \%$ above Filter B. The fraction of sub $23 \mathrm{~nm}$ particles is considerably lower with almost no such particles for the AM fit and Filter A. The fraction for Filter B and Filter C is 33\% and $40 \%$, respectively. This is half of the respective fractions as observed for TC1 and TC3. The GMD is higher for both TC2 and TC4 across most processing methods. For the raw PSD of TC2, the GMD is similar to TC1 and TC3 with $12.8 \mathrm{~nm}$, however, it is more than double for TC4 with $26.2 \mathrm{~nm}$. Likewise, the GMD for TC2 with Filter B and Filter C is above those of TC1 and TC 3 by ca. $5 \mathrm{~nm}$ and $7 \mathrm{~nm}$, respectively. Only for Filter A and the AM lognormal fit, the difference becomes up to three-fold. In contrast, the GMD for TC4 is four-fold or above for TC4 compared to the idling load conditions TC1 and TC3. For Filter $\mathrm{A}$ and the lognormal AM fit, the difference is even up to seven-fold.

Analysis of this data indicates that the influence of the processing method is most pronounced if the PSD contains both a nucleation type mode of particulates below $20 \mathrm{~nm}$ and an accumulation type mode of particles above $70 \mathrm{~nm}$. In such cases, the newly proposed Filter $\mathrm{C}$ can shift the GMD by up to $15 \mathrm{~nm}$. However, for any PSD with a pronounced nucleation type mode, the proposed filter increases the total PN by $10 \%$ to $17 \%$.

Table 4. Total particulate number (PN) emissions for the four test conditions (TCs) with different processing methods.

\begin{tabular}{lcccc}
\hline & \multicolumn{4}{c}{ Total PN $\left(\# / \mathrm{cm}^{3}\right)$} \\
Processing Method & TC1 & TC2 & TC3 & TC4 \\
\hline Lognormal Fit (NM) & $1.28 \times 10^{6}$ & $1.72 \times 10^{5}$ & $7.29 \times 10^{5}$ & $1.46 \times 10^{5}$ \\
Lognormal Fit (AM) & $6.20 \times 10^{4}$ & $2.01 \times 10^{4}$ & $1.95 \times 10^{4}$ & $8.92 \times 10^{4}$ \\
A: $\mathrm{d}_{50}=23 \mathrm{~nm}, \mathrm{~d}_{90}=41 \mathrm{~nm}$ & $1.54 \times 10^{5}$ & $3.36 \times 10^{4}$ & $1.06 \times 10^{5}$ & $8.94 \times 10^{4}$ \\
B: $\mathrm{d}_{50}=10 \mathrm{~nm}, \mathrm{~d}_{90}=15 \mathrm{~nm}$ & $7.42 \times 10^{5}$ & $1.03 \times 10^{5}$ & $5.07 \times 10^{5}$ & $1.34 \times 10^{5}$ \\
C: $\mathrm{d}_{65}=10 \mathrm{~nm}, \mathrm{~d}_{90}=15 \mathrm{~nm}$ & $8.50 \times 10^{5}$ & $1.20 \times 10^{5}$ & $5.59 \times 10^{5}$ & $1.47 \times 10^{5}$ \\
Discrete Lin. Approx. & $1.32 \times 10^{6}$ & $2.06 \times 10^{5}$ & $7.61 \times 10^{5}$ & $2.35 \times 10^{5}$ \\
\hline
\end{tabular}

Table 5. Fraction of sub $23 \mathrm{~nm}$ particulates of the total particulate number (PN) emissions for the four test conditions (TCs) with different processing methods.

\begin{tabular}{lcccc}
\hline \multirow{2}{*}{ Processing Method } & TC1 & TC2 & TC3 & TC4 \\
\hline Lognormal Fit (NM) & $94 \%$ & $96 \%$ & $90 \%$ & $99 \%$ \\
Lognormal Fit (AM) & $15 \%$ & $0.2 \%$ & $11 \%$ & $0.1 \%$ \\
A: $\mathrm{d}_{50}=23 \mathrm{~nm}, \mathrm{~d}_{90}=41 \mathrm{~nm}$ & $32 \%$ & $13 \%$ & $40 \%$ & $2 \%$ \\
B: $\mathrm{d}_{50}=10 \mathrm{~nm}, \mathrm{~d}_{90}=15 \mathrm{~nm}$ & $81 \%$ & $69 \%$ & $82 \%$ & $33 \%$ \\
C: $\mathrm{d}_{65}=10 \mathrm{~nm}, \mathrm{~d}_{90}=15 \mathrm{~nm}$ & $84 \%$ & $73 \%$ & $84 \%$ & $40 \%$ \\
Discrete Lin. Approx. & $89 \%$ & $84 \%$ & $88 \%$ & $62 \%$ \\
\hline
\end{tabular}

Table 6. Comparison of the number weighted geometric mean diameter (GMD) for different processing methods for the four test conditions (TCs).

\begin{tabular}{lcccc}
\hline & \multicolumn{4}{c}{ GMD $(\mathrm{nm})$} \\
Processing Method & TC1 & TC2 & TC3 & TC4 \\
\hline Lognormal Fit (NM) & 10.5 & 9.7 & 12.4 & 7.9 \\
Lognormal Fit (AM) & 49.4 & 168.5 & 46.7 & 195.3 \\
A: $\mathrm{d}_{50}=23 \mathrm{~nm}, \mathrm{~d}_{90}=41 \mathrm{~nm}$ & 33.2 & 82.6 & 26.8 & 187.2 \\
B: $\mathrm{d}_{50}=10 \mathrm{~nm}, \mathrm{~d}_{90}=15 \mathrm{~nm}$ & 15.7 & 22.5 & 15.8 & 73.3 \\
C: $\mathrm{d}_{65}=10 \mathrm{~nm}, \mathrm{~d}_{90}=15 \mathrm{~nm}$ & 14.5 & 19.7 & 15.0 & 59.7 \\
Discrete Lin. Approx. & 11.6 & 12.8 & 13.0 & 26.2 \\
\hline
\end{tabular}

\section{Conclusions}

Four operating conditions of a 1.0L GDI engine were analyzed for PN emissions. Different processing methods were applied to the obtained PSDs: Discrete linear approximation, lognormal function fitting, and counting efficiency modelling by digital filtering functions. The results highly depended on the shape of the PSD in terms of number and position of modes. Moreover, a new filtering function was proposed based on the previously established method of filtering functions. The function was designed to match the proposed counting efficiencies for an updated PMP covering sub $23 \mathrm{~nm}$ solid particulates. The following conclusions can be drawn from this study:

- Lognormal fitting for accumulation mode can be closely matched with a digital filtering function. The approach is useful for the scope of the previous PMP with the exclusion of sub $23 \mathrm{~nm}$ particles. However, with proposed changes particles of the corresponding nucleation type mode are included. Thus, this approach is not viable any longer.

- The new Filter C increases the total PN by $10 \%$ to $17 \%$ compared to the previous sub $23 \mathrm{~nm}$ Filter B. The PN levels are elevated even further if compared to the PMP type Filter A; by $64 \%$ to $452 \%$.

- The fraction of sub $23 \mathrm{~nm}$ particles is increased by $2 \%$ to $7 \%$ with the new Filter $\mathrm{C}$ compared to a previous Filter B designed for similar purposed. Compared to the PMP type Filter A, the increase is $38 \%$ to $60 \%$.

- The GMD is shifted towards smaller particle sizes by $0.8 \mathrm{~nm}$ to $13.6 \mathrm{~nm}$ with the new Filter $\mathrm{C}$ compared to the previous sub 23 $\mathrm{nm}$ Filter B and by $11.8 \mathrm{~nm}$ to $127.5 \mathrm{~nm}$ compared to the PMP type Filter A.

Regarding future work, the findings of this study should be verified for volatile artifacts. As no VPR was used, the observed concentrations for particles below $23 \mathrm{~nm}$ could be affected by the presence of volatile species. In line with the proposed changes to the PMP, employing an additional VPR such as a catalytic stripper would allow assessment of the proposed filter in comparable conditions. The methodology could subsequently be used for a larger-scale study to understand the formation of sub $23 \mathrm{~nm}$ particles under various operating conditions. Moreover, it would be of interest to compare the measurements obtained by a DMS with VPR and digital filter to measurement equipment that is compliant with the upcoming PMP regulations for sub $23 \mathrm{~nm}$ particulates. 


\section{References}

1. Qian, Y., Li, Z., Yu, L., Wang, X., et al., "Review of the stateof-the-art of particulate matter emissions from modern gasoline fueled engines," Appl. Energy 238:1269-1298, 2019, doi:10.1016/j.apenergy.2019.01.179.

2. Wang, B., Mosbach, S., Schmutzhard, S., Shuai, S., et al., "Modelling soot formation from wall films in a gasoline direct injection engine using a detailed population balance model," Appl. Energy 163:154-166, 2016, doi:10.1016/j.apenergy.2015.11.011.

3. Hageman, M.D., Sakai, S.S., and Rothamer, D.A., "Determination of soot onset and background particulate levels in a spark-ignition engine," Proc. Combust. Inst. 35(3):2949-2956, 2015, doi:10.1016/j.proci.2014.06.105.

4. Richter, H., and Howard, J.B., "Formation of polycyclic aromatic hydrocarbons and their growth to soot - A review of chemical reaction pathways," Prog. Energy Combust. Sci. 26(4-6):565-608, 2000, doi:10.1016/S0360-1285(00)000095.

5. Xi, J., and Zhong, B., "Soot in diesel combustion systems," Chem. Eng. Technol. 29(6):665-673, 2006, doi:10.1002/ceat.200600016.

6. Vishwanathan, G., and Reitz, R.D., "Modeling soot formation using reduced polycyclic aromatic hydrocarbon chemistry in n-heptane lifted flames with application to low temperature combustion," J. Eng. Gas Turbines Power 131(3):32801, 2009, doi:10.1115/1.3043806.

7. Johansson, K.O., Head-Gordon, M.P., Schrader, P.E., Wilson, K.R., et al., "Resonance-stabilized hydrocarbonradical chain reactions may explain soot inception and growth," Science (80-. ). 361(6406):997-1000, 2018, doi:10.1126/science.aat3417.

8. Tree, D.R., and Svensson, K.I., "Soot processes in compression ignition engines," Prog. Energy Combust. Sci. 33(3):272-309, 2007, doi:10.1016/j.pecs.2006.03.002.

9. Clague, A.D.H., Donnet, J.B., Wang, T.K., and Peng, J.C.M., "A comparison of diesel engine soot with carbon black," Carbon N. Y. 37(10):1553-1565, 1999, doi:10.1016/S00086223(99)00035-4.

10. Ishiguro, T., Takatori, Y., and Akihama, K., "Microstructure of diesel soot particles probed by electron microscopy: First observation of inner core and outer shell," Combust. Flame 108(1-2):231-234, 1997, doi:10.1016/S00102180(96)00206-4.

11. Morgan, N., Kraft, M., Balthasar, M., Wong, D., et al., "Numerical simulations of soot aggregation in premixed laminar flames," Proc. Combust. Inst. 31(1):693-700, 2007, doi:10.1016/j.proci.2006.08.021.

12. Müller, J.-O., Su, D.S., Wild, U., and Schlögl, R., "Bulk and surface structural investigations of diesel engine soot and carbon black," Phys. Chem. Chem. Phys. 9(30):4018-4025, 2007, doi:10.1039/b704850e.
13. La Rocca, A., Bonatesta, F., Fay, M.W., and Campanella, F., "Characterisation of soot in oil from a gasoline direct injection engine using transmission electron microscopy," Tribol. Int. 86:77-84, 2015, doi:10.1016/j.triboint.2015.01.025.

14. Omidvarborna, H., Kumar, A., and Kim, D.-S., "Recent studies on soot modeling for diesel combustion," Renew. Sustain. Energy Rev. 48:635-647, 2015 , doi:10.1016/j.rser.2015.04.019.

15. Stanmore, B.R., Brilhac, J.-F., and Gilot, P., "The oxidation of soot: A review of experiments, mechanisms and models," Carbon N. Y. 39(15):2247-2268, 2001, doi:10.1016/S00086223(01)00109-9.

16. Service, R.F., "Climate change: Study fingers soot as a major player in global warming," Science (80-. ). 319(5871):1745, 2008, doi:10.1126/science.319.5871.1745.

17. Mari, X., Lefèvre, J., Torréton, J.-P., Bettarel, Y., et al., "Effects of soot deposition on particle dynamics and microbial processes in marine surface waters," Global Biogeochem. Cycles 28(7):662-678, 2014, doi:10.1002/2014GB004878.

18. Oberdörster, G., Oberdörster, E., and Oberdörster, J., "Nanotoxicology: An emerging discipline evolving from studies of ultrafine particles," Environ. Health Perspect. 113(7):823-839, 2005, doi:10.1289/ehp.7339.

19. Green, D.A., and Lewis, R., "The effects of sootcontaminated engine oil on wear and friction: A review," Proc. Inst. Mech. Eng. Part D J. Automob. Eng. 222(9):16691689, 2008, doi:10.1243/09544070JAUTO468.

20. Antusch, S., Dienwiebel, M., Nold, E., Albers, P., et al., "On the tribochemical action of engine soot," Wear 269(1-2):112, 2010, doi:10.1016/j.wear.2010.02.028.

21. George, S., Balla, S., Gautam, V., and Gautam, M., "Effect of diesel soot on lubricant oil viscosity," Tribol. Int. 40(5):809_ 818, 2007, doi:10.1016/j.triboint.2006.08.002.

22. "Council Directive 91/441/EEC of 26 June 1991 amending Directive 70/220/EEC on the approximation of the laws of the Member States relating to measures to be taken against air pollution by emissions from motor vehicles," Off. J. Eur. Communities L242:1-106, 1991, https://eurlex.europa.eu/eli/dir/1991/441/oj (accessed July 6, 2020).

23. Braisher, M., Stone, R., and Price, P., "Particle number emissions from a range of european vehicles," SAE Technical Paper 2010-01-0786, 2010, doi:10.4271/2010-01-0786.

24. Giechaskiel, B., Mamakos, A., Andersson, J., Dilara, P., et al., "Measurement of automotive nonvolatile particle number emissions within the European legislative framework: A review," Aerosol Sci. Technol. 46(7):719-749, 2012, doi:10.1080/02786826.2012.661103.

25. "Directive 98/69/EC of the European Parliament and of the Council of 13 October 1998 relating to measures to be taken against air pollution by emissions from motor vehicles and amending Council Directive 70/220/EEC," Off. J. Eur. Communities L350:1-57, 1998, https://eurlex.europa.eu/eli/dir/1998/69/oj (accessed July 6, 2020). 
26.

Giechaskiel, B., Dilara, P., and Andersson, J., "Particle measurement programme (PMP) light-duty inter-laboratory exercise: Repeatability and reproducibility of the particle number method," Aerosol Sci. Technol. 42(7):528-543, 2008, doi:10.1080/02786820802220241.

27. Giechaskiel, B., Maricq, M., Ntziachristos, L., Dardiotis, C., et al., "Review of motor vehicle particulate emissions sampling and measurement: From smoke and filter mass to particle number," J. Aerosol Sci. 67:48-86, 2014, doi:10.1016/j.jaerosci.2013.09.003.

28. "Commission Regulation (EU) 2016/646 of 20 April 2016 amending Regulation (EC) No 692/2008 as regards emissions from light passenger and commercial vehicles (Euro 6)," Off. J. Eur. Union L109:1-22, 2016, https://eurlex.europa.eu/legalcontent/EN/TXT/?uri=CELEX:32016R0646 (accessed July $6,2020)$

29. Lapuerta, M., Oliva, F., Agudelo, J.R., and Boehman, A.L., "Effect of fuel on the soot nanostructure and consequences on loading and regeneration of diesel particulate filters," Combust. Flame 159(2):844-853, 2012, doi:10.1016/j.combustflame.2011.09.003.

30. He, X., Ratcliff, M.A., and Zigler, B.T., "Effects of gasoline direct injection engine operating parameters on particle number emissions," Energy \& Fuels 26(4):2014-2027, 2012, doi:10.1021/ef201917p.

31. Kulkarni, P., Baron, P.A., and Willeke, K., eds., Aerosol measurement: Principles, techniques, and applications, 3rd ed., John Wiley \& Sons, Hoboken, NJ, USA, 2011, doi:10.1002/9781118001684

32. Symonds, J.P.R., Reavell, K.S.J., Olfert, J.S., Campbell, B.W., et al., "Diesel soot mass calculation in real-time with a differential mobility spectrometer," J. Aerosol Sci. 38(1):5268, 2007, doi:10.1016/j.jaerosci.2006.10.001.

33. Zinola, S., Leblanc, M., Rouleau, L., Dunand, X., et al., "Measurement of Sub-23 nm particles emitted by gasoline direct injection engine with new advanced instrumentation," SAE Technical Paper 2019-01-2195, 2019, doi:10.4271/2019-01-2195.

34. Leach, F.C.P., "Particulate emissions from gasoline direct injection engines," PhD thesis, University of Oxford, 2014.

35. Leach, F., Stone, R., Richardson, D., Lewis, A., et al., "Particulate emissions from a highly boosted gasoline direct injection engine," Int. J. Engine Res. 19(3):347-359, 2018, doi:10.1177/1468087417710583.

36. Leach, F.C.P., Stone, R., Richardson, D., Turner, J.W.G., et al., "The effect of oxygenate fuels on PN emissions from a highly boosted GDI engine," Fuel 225:277-286, 2018, doi:10.1016/j.fuel.2018.03.148.

37. Leach, F.C.P., Stone, R., Richardson, D., Lewis, A.G.J., et al., "The effect of fuel composition on particulate emissions from a highly boosted GDI engine - An evaluation of three particulate indices," Fuel 252:598-611, 2019, doi:10.1016/j.fuel.2019.04.115.
38. Leach, F., Lewis, A., Akehurst, S., Turner, J., et al., "Sub-23 nm Particulate Emissions from a Highly Boosted GDI Engine," SAE Technical Paper 2019-24-0153, 2019, doi:10.4271/2019-24-0153.

39. Giechaskiel, B., Lähde, T., Suarez-Bertoa, R., Clairotte, M., et al., "Particle number measurements in the European legislation and future JRC activities," Combust. Engines 174(3):3-16, 2018, doi:10.19206/CE-2018-301.

40. Horn, H.G., "PEMs4Nano Report: Calibrated CPC with D50 $<=10 \mathrm{~nm}$ for laboratory use - Together with the documented calibration procedure,", 2017, https://pems4nano.eu/results/ (accessed July 5, 2020).

41. Kumar, P., Fennell, P., Symonds, J., and Britter, R., "Treatment of losses of ultrafine aerosol particles in long sampling tubes during ambient measurements," Atmos. Environ. 42(38):8819-8826, 2008, doi:10.1016/j.atmosenv.2008.09.003.

42. United Nations Economic Commission for Europe, "PMP Web Conference 11 May 2020,", 2020, https://wiki.unece.org/display/trans/PMP+Web+Conference +11+May+2020 (accessed July 5, 2020).

43. United Nations Economic Commission for Europe, "PMP 52nd Session,", 2020, https://wiki.unece.org/display/trans/PMP+52th+Session (accessed July 5, 2020).

44. United Nations Economic Commission for Europe, "Final report on the development of Amendment 6 to global technical regulation No. 15 on worldwide harmonized light vehicles test procedures (WLTP), Informal document GRPE81-15,",

2020 , https://www.unece.org/trans/main/wp29/wp29wgs/wp29grp e/grpeinf81.html (accessed July 5, 2020).

\section{Contact Information}

Correspondence to: Sebastian Pfau, Powertrain Research Group, Department of Mechanical Materials and Manufacturing Engineering, The University of Nottingham, Nottingham, NG7 2RD, U.K. sebastian.pfau@nottingham.ac.uk

\section{Acknowledgments}

The authors thank John Lane, Nigel Sykes, and Paul Bramman for technical support with the engine setup. This work was supported by the Engineering and Physical Sciences Research Council through the scholarship provided by the EPSRC Thematic Programme in LowDimensional Materials and Interfaces for Sebastian Pfau [grant number EP/N50970X/1].

\section{Definitions/Abbreviations}

$\begin{array}{ll}\text { AM } & \text { Accumulation Mode } \\ \text { aTDC } & \text { After Top Dead Center } \\ \text { bTDC } & \text { Before Top Dead Center } \\ \text { CA } & \text { Crank Angle } \\ \text { CA50 } & \text { Crank Angle for 50\% of Total Heat Released }\end{array}$




$\begin{array}{ll}\text { CMD } & \text { Count Median Diameter } \\ \text { CoV } & \text { Coefficient of Variance } \\ \text { CPC } & \text { Condensation Particle Counter } \\ \text { d50 } & \text { Cut-Off Size for 50\% Counting Efficiency } \\ \text { d65 } & \text { Cut-Off Size for 65\% Counting Efficiency } \\ \text { d90 } & \text { Cut-Off Size for 90\% Counting Efficiency } \\ \text { DMA } & \text { Differential Mobility Analyzer } \\ \text { DMS } & \text { Differential Mobility Spectrometer } \\ \text { dp } & \text { Particle Diameter } \\ \text { ECU } & \text { Engine Control Unit } \\ \text { EVC } & \text { Exhaust Valve Closing } \\ \text { GDI } & \text { Gasoline Direct Injection } \\ \text { GSD } & \text { Geometric Standard Deviation } \\ \text { HEPA } & \text { High-Efficiency Particle Air } \\ \text { IMEPn } & \text { Net Indicated Mean Effective Pressure } \\ \text { IVO } & \text { Intake Valve Opening } \\ \text { NM } & \text { Nucleation Mode } \\ \text { np } & \text { Particle Concentration } \\ \text { PM } & \text { Particulate Mass } \\ \text { PMP } & \text { Particle Measurement Programme } \\ \text { PN } & \text { Particulate Number } \\ \text { PSD } & \text { Particle Size Distribution } \\ \text { SOI } & \text { Start of Injection } \\ \text { TC } & \text { Vest Condition } \\ \text { VPR } & \text { Variable Valve Timing } \\ \text { Varticle Remover } \\ \text { DMT }\end{array}$

